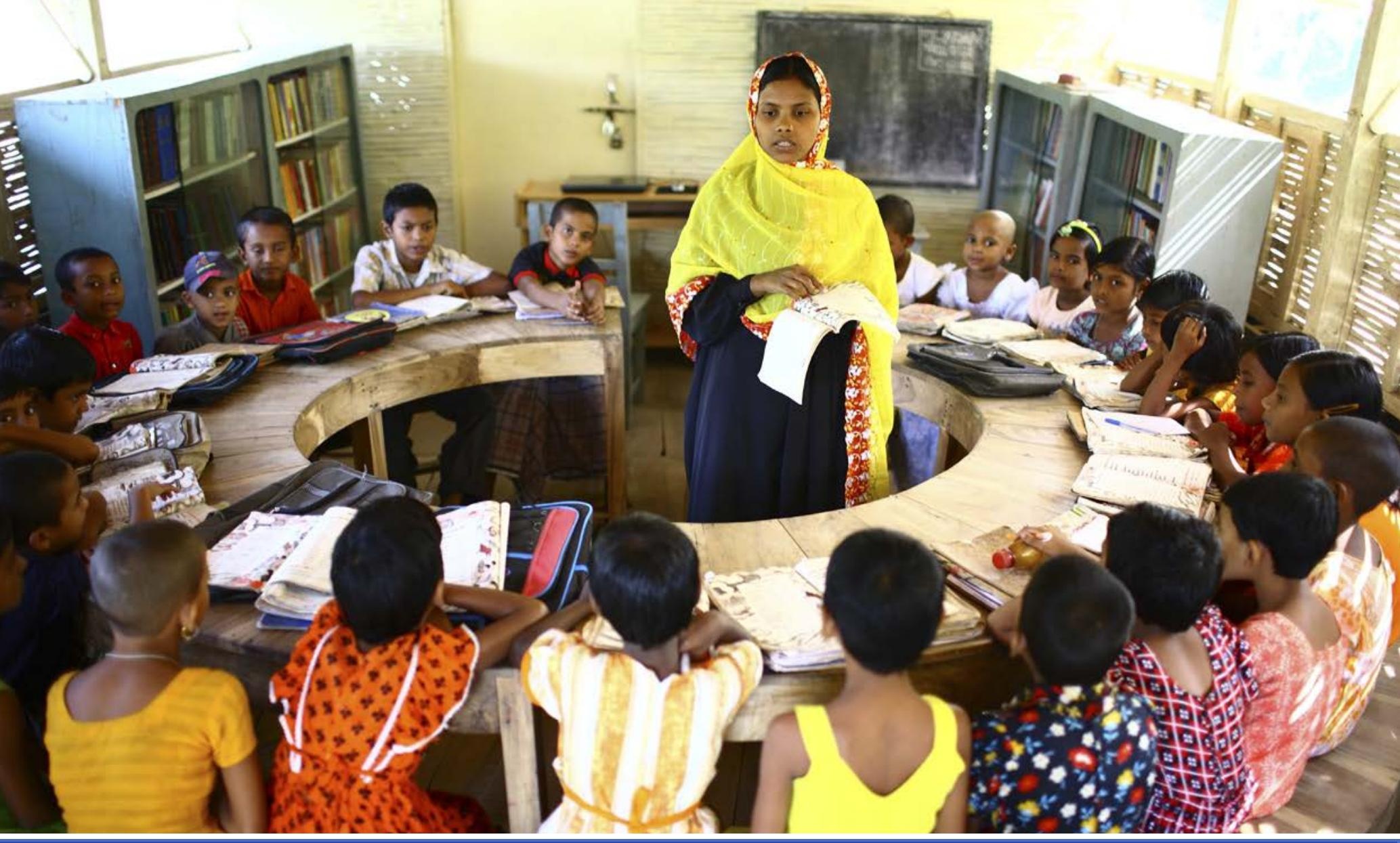

\title{
ACCELERATING THE CONTRIBUTION THAT NUTRITION'S UNDERLYING DRIVERS MAKE TO NUTRITION IMPROVEMENTS
}

\section{-HE FOOD, SOCIAL, HEALTH, AND LIVING ENVIRONMENTS IN WHICH PEOPLE MAKE DECISIONS HAVE A HUGE INFLUENCE ON NUTRITIONAL STATUS (FIGURE 6.1).}

For optimal nutrition, these underlying factors matter. For example, the food environment should make healthy diets available, affordable, accessible, and desirable. The social environment should set norms about good nutrition and hygiene and support people in caring for their nutrition and the nutrition of their families.

The health environment should support widespread access to affordable and high-quality preventive and curative health care. And the living environment should provide access to improved water and sanitation services, as well as built spaces that promote physical activity in safe and healthy contexts. Behind these underlying outcomes are underlying processes such as agricultural development, trade, health care, education, and poverty reduction. All of these processes are influenced by governance systems and economic incentives and disincentives. Together these underlying outcomes and processes form what we term the "underlying drivers" of nutrition status.

Government resources that influence these under lying drivers dwarf the resources allocated to actions explicitly designed to address nutrition. The 2014 Global Nutrition Report found that 35 percent and 31 percent of government budgets in Africa and Asia, respectively, are allocated to just four sectors: agriculture, health, education, and social protection. In contrast, the 2015 Global Nutrition Report found that the average allocation to nutrition across these sectors (including the water and sanitation sector) from 14 countries was 1.3 percent. The large amount of resources flowing to these underlying drivers makes it imperative that the nutrition community make it easier for those working in the relevant sectors to identify nutrition-related commitments and implement them

This chapter asks what commitments to action, when kept, are likely to accelerate the pace of 
improvement in these underlying drivers and their impact on nutrition. First, the chapter reviews new evidence on the importance of these underlying drivers for nutrition. Second, it examines three sets of actions designed to enhance the contribution underlying drivers can make to improving nutrition by making these drivers more nutrition sensitive: (1) actions to accelerate the progress of the drivers themselves, (2) actions that help these drivers have a bigger nutrition impact, and (3) actions that exploit the opportunities these drivers provide as platforms for more immediate nutrition-improving initiatives (Ruel and Alderman 2013). The chapter concludes with calls to action.

\section{THE IMPORTANCE OF UNDERLYING DRIVERS TO NUTRITION IMPROVEMENT}

Underlying drivers are important for all forms of malnutrition. The most comprehensive evidence base is for the correlation between selected underlying drivers and stunting outcomes, but it is likely that these drivers are also highly relevant for other forms of undernutrition, such as wasting and anemia. These underlying drivers include calories from the food supply, the percentage of calories from staples, female secondary school enrollment rates, the life expectancy of women relative to men, and access to improved

This chapter asks what commitments to action, when kept, are likely to accelerate the pace of improvement in the underlying drivers and their impact on nutrition?

- Well over 30 percent of government spending in Africa and Asia is allocated to five sectors that serve as underlying drivers of nutrition: agriculture; health; education; social protection; and water, sanitation, and hygiene. Policies and programs in these areas can be adjusted to improve nutrition outcomes in many ways, such as focusing on women's empowerment, and building nutrition targets and nutrition behavior change components into program design. This chapter contains examples of how these adjustments can be made.

- Direct undernutrition interventions, even when scaled up to 90 percent coverage rates, have been estimated to address only 20 percent of the stunting burden. Tackling the underlying drivers of nutrition, particularly in the sectors listed above, is key to addressing the other 80 percent.

- With diet the number-one factor in the global burden of disease, changes in food production, food storage and distribution, cross-border trade, and food packaging and processing could have a significant impact on diet- and nutrition-related noncommunicable diseases. This chapter outlines how.

- Across all drivers, the power of women to make and influence key decisions is essential to improving nutrition outcomes: a mother with a secondary school education is less likely to have a malnourished child.

- Climate change - including the El Niño weather effects of 2015-2016-and conflict have significantly increased the caseload of severe acute malnutrition, underscoring the importance of aligning humanitarian food assistance strategies and implementation across different agencies.

- We have a good understanding of the set of underlying drivers that are most important for reducing stunting, but their relative importance varies by country. The analysis in this chapter will help countries identify which underlying drivers they should prioritize.

- Income, urbanization, and globalization have been identified as underlying drivers of obesity and overweight, but more research is needed to understand the set of drivers that all forms of malnutrition have in common. 


\section{FIGURE 6.1 The underlying drivers of improved nutrition status}

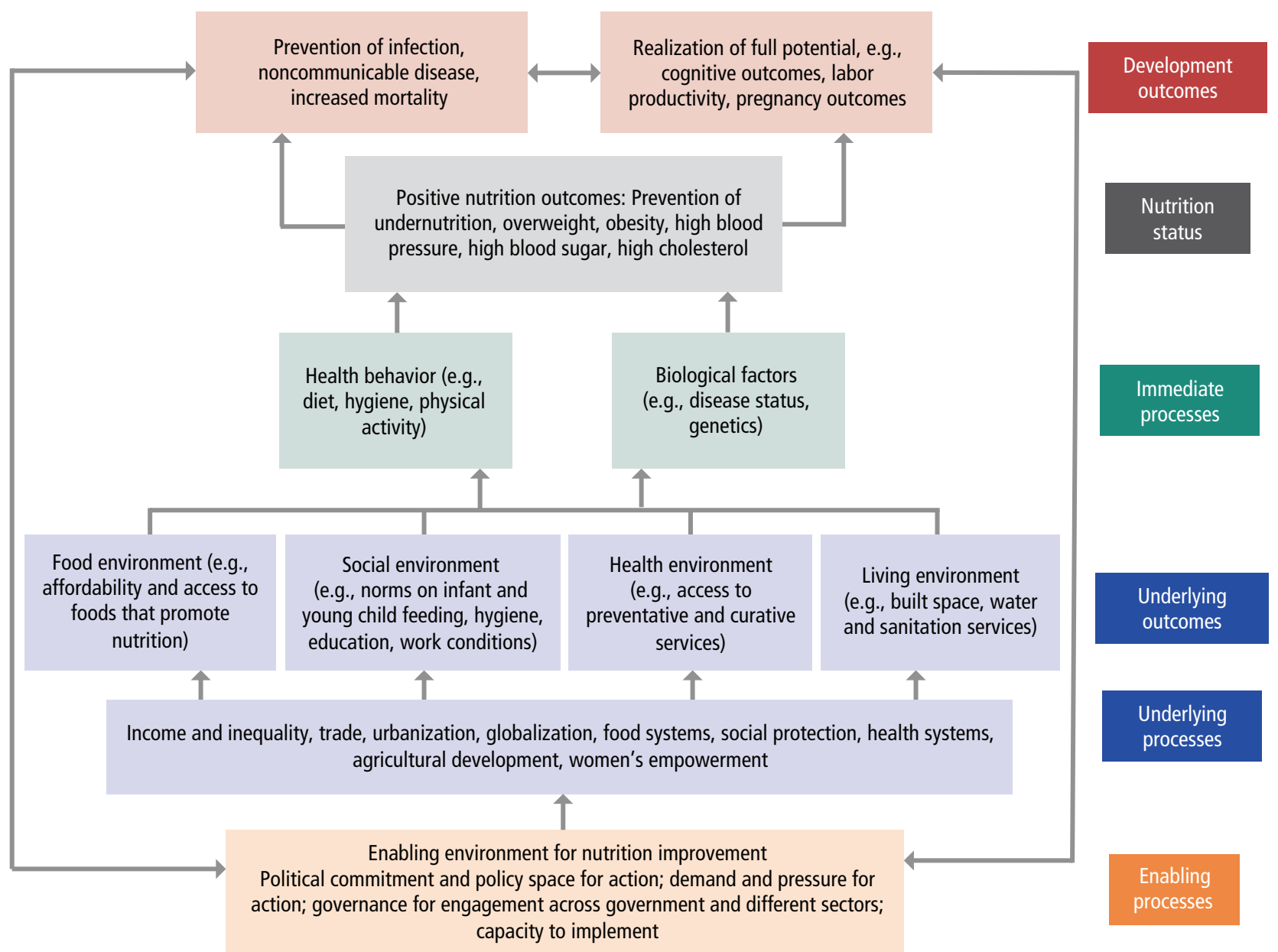

Source: Authors.

Note: Underlying drivers combine underlying outcomes and underlying processes.

water sources and sanitation services. For other forms of malnutrition, such as overweight and obesity, the evidence is more complex and fractured.

The importance of underlying drivers to efforts to reduce undernutrition is evident in two main respects: First, direct undernutrition interventions, even when scaled up to 90 percent coverage rates in 34 high-burden countries, have been estimated to address only 20 percent of their stunting deficits (Bhutta et al. 2013). There is clearly a significant gap to be filled, in part, by drivers at the underlying level. Second, the World Bank and the Results for Development Institute have estimated the costs of achieving the World Health Assembly (WHA) targets by 2025 by scaling up direct nutrition interventions (in the Global Nutrition Report 2015 and in this year's Global Nutrition Report, Chapter 7), and these cost estimates depend on assumptions about the contributions underlying drivers can make. If underlying drivers can make a larger contribution over time, then it may be possible to scale up direct nutrition interventions more slowly.

Several studies provide estimates that link stunting to a range of underlying drivers. Smith and Haddad (2015) analyzed variation across a number of countries over time, while Headey and Hoddinott (2014) and Headey (forthcoming) analyzed variation within a given country over time. ${ }^{1}$ Figure 6.2 summarizes the estimated contributions to under- 5 height-for-age (standardized) made by the same set of underlying drivers in four South Asian countries over the past decade: Bangladesh, India, Nepal, and Pakistan. ${ }^{2}$

Assets, women's education, and open defecation are important across all four countries, reflecting stunting's multisectoral etiology. 


\section{PANEL 6.1 ACTIONS THAT APPEAR TO HAVE IMPROVED NUTRITIONAL STATUS IN GHANA}

\section{RICHMOND ARYEETEY, ESI COLECRAFT, AND ANNA LARTEY}

Erom 1988 to 2003, four successive Demographic and Health Surveys (DHSs) in Ghana reported a slow decline in under-5 stunting rates, with prevalence remaining greater than 30 percent. After 2008, though, the decline in stunting accelerated, and the 2014 DHS reported a stunting prevalence of 19 percent (GSS et al. 2015).

These improvements are likely linked to political stability and faster economic growth. Ghana's peaceful democratic process has become a model for Africa. Since 1992, governments have changed democratically, without major disruptions to social programs. And economic growth in Ghana accelerated from 5 percent in 2009 to well above 5 percent in 2010-2013, returning to 5 percent in 2014. Economic growth is not necessary or sufficient to reduce undernutrition, but it is helpful, especially if it is broad based, because it enables families to buy more and better-quality nutrition inputs and helps government provide more public services as tax revenues increase.

In addition to changes in underlying political and economic drivers, Ghana has implemented a wide range of policies and interventions affecting the immediate and underlying causes of undernutrition, such as the following:

- Since 2008 the government has increased coverage of interventions such as free distribution of insecticide-treated bed nets to pregnant women and focused prenatal care. Maternal thinness (a body mass index of less than 18.5) in Ghana has declined significantly from 8 percent in 2008 to 6 percent in 2014.

- In the past decade, the implementation of community-based management of acute malnutrition has also been scaled up, but not yet in all facilities.

- The Ministry of Health adopted a comprehensive "child-centered" child health strategy in 2007 (Ghana, Ministry of Health 2007). This led to increased coverage of interventions for malaria prevention and control, use of insecticide-treated bed nets, intermittent treatment of malaria in pregnancy, and prompt treatment of childhood fever. Implementation of these interventions has consistently and greatly improved, leading to a reduced fever rate over time. Similar declines have occurred for childhood diarrhea and acute respiratory infections (ARIs). There is also increased uptake of effective interventions such as zinc and oral rehydration solutions for diarrhea treatment, antibiotics for ARIs, and vaccinations for children 12-23 months old. These factors have likely contributed to Ghana's significant progress in reducing the burden of infections and disease.

- Agriculture contributes the largest share of Ghana's GDP (Ghana, Ministry of Food and Agriculture 2010). Ghana is one of the few countries in Africa south of the Sahara that met the Millennium Development Goal $1 \mathrm{C}$ targets on hunger and poverty reduction (FAO 2015a). Ghana's agricultural policy emphasizes rural agricultural development, irrigation, and improved crop varieties and input subsidies for farm families (Ghana, Ministry of Food and Agriculture 2010). Agricultural interventions have become more oriented toward nutrition by promoting backyard gardens with nutrient-rich crops like orange-fleshed sweet potatoes; fruit tree planting; and rearing of small ruminants, snails, and poultry.

- Ghana has instituted social protection measures. The National Health Insurance Scheme, started in 2003, has removed financial barriers to health-care access, enabling poor households, paying lower premiums, to gain access to high-quality healthcare (Saleh 2013). The social transfer program (Livelihood Empowerment against Poverty) currently provides cash grants to more than 80,000 ultra-poor households (Roelen et al. 2015). Free maternal health coverage for prenatal care, deliveries, and early postnatal care was instituted in 2010 to encourage women to seek appropriate pregnancy and delivery care. The homegrown National School Feeding Program provides one hot meal daily to children in targeted basic schools in almost 200 districts (Ofei-Aboagye 2013).

- The government has a policy on free basic education and capacitation grants. The Ghana Living Standards Surveys (2000, 2008, and 2014) suggest steady improvements in female education. The proportion of females 15 and older who have never been to school declined marginally (41 percent to 38 percent) between 2000 and 2008, but more significantly, to 24 percent by 2014 (GSS 2014). Also, between 2000 and 2008, the female literacy rate increased from 27 percent to 31 percent (GSS et al. 2015). The share of females with secondary education or higher remains low (12 percent), although it has doubled since 2000.

Despite the reported progress, challenges and opportunities remain. Agricultural policy could be more oriented toward nutrition outcomes, recent declines in exclusive breastfeeding rates need to be reversed, and the quality of diets of infants and young children needs to be improved significantly. Furthermore, reductions in stunting are not equally distributed. For example, the Northern Region has 30 percent stunting, compared with 10 percent in the Greater Accra Region. And while government policy interventions support nutrition, financial commitment remains suboptimal (Laar et al. 2015).

Moreover, obesity and noncommunicable disease risk factor rates are rising. The prevalence of adult overweight and obesity (body mass index greater than or equal to 25) increased from 30 percent to 34 percent between 2010 and 2014 (WHO 2014b). Rates among women were higher: 44 percent in 2014. Hypertension among adults is also widespread-42 percent in 2008. The 2012 National Policy for the Prevention and Control of Chronic Non-communicable Diseases in Ghana appears not to have been operationalized in any way. 


\section{FIGURE 6.2 Contributions of different underlying factors to estimated reductions in standardized height-for-age, children under 5 years of age}

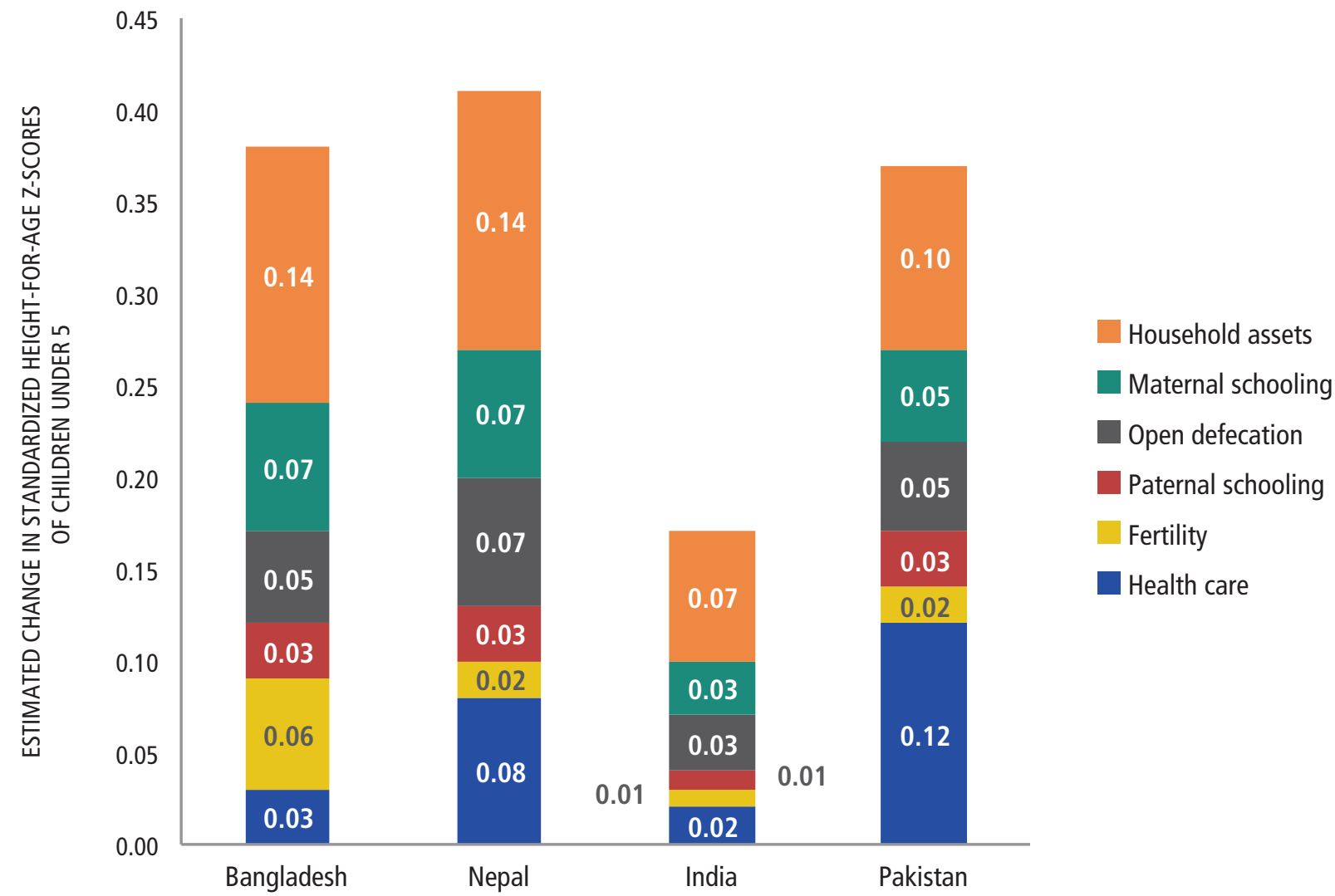

Source: Headey (forthcoming).

In a more qualitative analysis of Ghana's fast rates of stunting reduction (from more than 30 percent in 2003 to 19 percent in 2014), Panel 6.1 illustrates the important role that a range of underlying factors play, especially in combination with improvements in coverage of more direct nutrition interventions.

A different set of underlying drivers have been examined for risk factors and markers of nutrition-related noncommunicable diseases (NCDs): body mass index (BMI), overweight and obesity rates, fasting plasma glucose, systolic blood pressure, and serum total fasting cholesterol.

A range of cross-country studies examine the relationship between some underlying drivers and BMI, overweight, and obesity outcomes directly. Some of the findings are as follows:

- For income, studies indicate a positive association between national income and obesity for low- and middle-income countries (for example, Ruel and Alderman 2013). There is a positive relationship between household assets and female obesity, up to about US $\$ 7,000$, where it flattens off (Goryakin and Suhrcke 2014). Similarly, for a large set of countries from low-, middle-, and high-income levels, Danaei and colleagues (2013) reported that adult BMI rises with per capita national income up to about US\$7,000, and then flattens. However, Neuman et al. (2014), using DHS data from low- and middle-income countries, found no association between national income and mean BMI. For education, there is a positive association with overweight for women, with a declining risk for those with higher education (Mamun and Finlay 2015, using DHS surveys from low- and middle-income countries).

- The living environment, especially living in an urban area, shows a consistent relationship with these nutrition outcomes. For a wide range of countries, living in an urban area is positively associated with overweight in women (Goryakin and Suhrcke 2014; Goryakin et al. 2015), adult BMI (Danaei et al. 2013), and ischemic heart disease (Harrington and Elliott 2009; Green et al. 2016). Evidence from Latin America suggests that food environments are increasingly dominated by "ultra-processed" foods, driven by underlying drivers such as urbanization, income, and market deregulation (PAHO 2015b). 
- For globalization, these studies offer inconsistent directions and strengths of association between a range of globalization indicators and both obesity and NCD-related outcomes. For example, on trade openness, Neuman et al. (2014) found no association with BMI while Miljkovic et al. (2015) found positive associations with obesity. For foreign direct investment, Neuman et al. (2014) found no association with BMI, and Miljkovic et al. (2015) found no association with obesity. For indexes of globalization, Goryakin et al. (2015) found stronger associations between overweight/obesity and the social and political dimensions of globalization, compared with the economic dimensions.

More work is needed to unify a number of empirical research strands on the underlying drivers of obesity and nutrition-related NCDs and their risk factors. Replication of cross-country studies, better data, and advanced analytical methods are needed to increase confidence in the results. We also need to better understand where underlying drivers for undernutrition co-occur with obesity and nutritionrelated NCDs.

\section{ACTIONS TO ENHANCE THE CONTRIBUTION OF UNDERLYING DRIVERS TO NUTRITION IMPROVEMENT}

Here we review actions to enhance the contribution of the underlying drivers, outcomes, and processes outlined in Figure 6.1 to improving nutrition status. We focus on three avenues for doing so: (1) by altering the rate of change in underlying drivers, (2) by redesigning them to orient them toward achieving nutrition outcomes, and (3) by using them as a platform for direct nutrition interventions.

\section{ACCELERATING THE RATE OF CHANGE OF UNDERLYING DRIVERS}

The ways in which changes in the underlying drivers in Figure 6.1 can be guided to reduce undernutrition are well known and have been articulated in many articles and reports. National and household food security is achieved through a combination of investments in agriculture (for example, Godfray et al. 2010 globally), antipoverty programs (Devereux 2015 for Africa south of the Sahara; Dutta et al. 2012 for India), and food policy (Bray and Popkin 2014 for the United States; Rocha 2016 for Brazil). Expansion of improved water and sanitation (Fuller et al. 2016 globally; Duflo et al. 2015 for India) is dependent on the level of development and on governance (Smith and Haddad 2015). Access to improved healthcare is driven by political leadership, health system reform, and public and private investment (for example, Savedoff et al. 2012 for the United States; Frenk 2015 for Latin America; Reddy 2015 for India). The agency of women is vital to strengthening the contribution of all of these underlying drivers to improved nutrition outcomes (Cunningham et al. 2015; Carlson et al. 2015; Rollins et al. 2016).

But how best to make more strategic commitments at the underlying level? Reflecting the availability of recent evidence, here we focus on stunting and six underlying drivers (Smith and Haddad 2015). To help countries be more strategic in identifying underlying drivers that are lagging relative to others, we identify thresholds for the drivers, above which stunting is greater than 15 percent. A 15 percent stunting cutoff is arbitrary but does correspond to the approximate stunting prevalence in 2015 for 100 million stunted children-the WHA target for stunting in 2025 (IFPRI 2014). The underlying driver thresholds are calculated in a simple way: we fit a line to a cross-plot of stunting and each of the underlying drivers using data from all countries that have available data for all six underlying drivers. The threshold for, say, available calories per person per day is determined by the calorie level above which we would estimate a stunting rate_-on average — of less than 15 percent $(2,850$ calories). This is done for all six underlying drivers (Table 6.1).

These thresholds can serve as a useful starting point for countries to begin thinking about targets for their

\section{TABLE 6.1 Thresholds for underlying drivers corresponding to a predicted stunting rate of less than 15 percent}

\begin{tabular}{|l|c|c|}
\hline Underlying driver & $\begin{array}{c}\text { Threshold corresponding to a prediction } \\
\text { of stunting prevalence of }<\mathbf{1 5 \%}\end{array}$ \\
\hline Total per capita calories in food supply & 2,850 & 51 \\
\hline Calories from nonstaples & 69 & Calories \\
\hline Access to improved water & 76 & Percentage \\
\hline Access to improved sanitation & 81 & Percentage \\
\hline Female secondary school enrollment rate & 1.072 & Percentage \\
\hline Ratio of female to male life expectancy (as a proxy for the empowerment of women) & Ratio \\
\hline
\end{tabular}

Source: Authors. 


\section{TABLE 6.2 Number of countries by number of vulnerabilities}

\begin{tabular}{|c|c|c|}
\hline $\begin{array}{l}\text { Number of } \\
\text { vulnerabilities }\end{array}$ & $\begin{array}{l}\text { Number of } \\
\text { countries }\end{array}$ & Names of countries $(n=98)$ \\
\hline 0 & 6 & Argentina, Armenia, Belarus, Brazil, Turkey, Venezuela \\
\hline 1 & 14 & $\begin{array}{l}\text { Albania, Barbados, Belize, Chile, Colombia, Ecuador, Japan, Kazakhstan, Mexico, Montenegro, Serbia, The former } \\
\text { Yugoslav Republic of Macedonia, United States, Uruguay }\end{array}$ \\
\hline 2 & 14 & $\begin{array}{l}\text { Algeria, Azerbaijan, Costa Rica, Dominican Republic, Egypt, Guyana, Honduras, Iran, Jordan, Kyrgyzstan, South Africa, } \\
\text { Suriname, Thailand, Tunisia }\end{array}$ \\
\hline 3 & 14 & $\begin{array}{l}\text { China, El Salvador, Guatemala, Iraq, Jamaica, Malaysia, Maldives, Mongolia, Panama, Paraguay, Peru, Republic of } \\
\text { Moldova, Sri Lanka, Tajikistan }\end{array}$ \\
\hline 4 & 4 & Botswana, Morocco, Philippines, Sao Tome and Principe \\
\hline 5 & 11 & $\begin{array}{l}\text { Benin, Bolivia, Cambodia, Central African Republic, Ghana, Indonesia, Mauritania, Namibia, Nicaragua, Uganda, } \\
\text { Vanuatu }\end{array}$ \\
\hline 6 & 35 & $\begin{array}{l}\text { Angola, Bangladesh, Burkina Faso, Cameroon, Chad, Congo, Côte d’Ivoire, Djibouti, Ethiopia, Gabon, Gambia, Guinea, } \\
\text { Guinea-Bissau, India, Kenya, Lao People's Democratic Republic, Lesotho, Liberia, Madagascar, Malawi, Mali, Mozam- } \\
\text { bique, Nepal, Niger, Nigeria, Pakistan, Rwanda, Senegal, Sierra Leone, Solomon Islands, Swaziland, Timor-Leste, Togo, } \\
\text { Tanzania, Zimbabwe }\end{array}$ \\
\hline
\end{tabular}

Source: Authors.

underlying drivers - at least for stunting reductions. ${ }^{3}$ The thresholds will be different for other nutrition outcomes such as under-five overweight. For countries with significant levels of undernutrition and overweight/obesity, the threshold on calorie availability needs to be interpreted with care.

If countries show underlying determinant levels below the thresholds in Table 6.1, we can say they have a vulnerability to stunting in this underlying area. Table 6.2 ranks countries by their number of vulnerabilities. For countries with zero and six vulnerabilities, the exercise does not assist much in prioritization, although it is useful to have the values of these underlying drivers in the same place for reference (Appendix Table A6.1).

Of course the aim should be to improve all underlying drivers at the same time, but because resources are scarce and have alternative uses, it is important to have some information to feed into the prioritization process.

\section{REORIENTING UNDERLYING DRIVERS TOWARD ACHIEVING NUTRITION OUTCOMES}

The Global Nutrition Reports of 2014 and 2015 provided examples of interventions in agriculture and social protection that have attempted to reorient underlying drivers toward achieving nutrition outcomes. The 2014 Global Nutrition Report described the impact evaluation results of the Helen Keller International home garden program in Burkina Faso and identified key attributes that were important for enhancing nutritional impacts. The 2015 Global Nutrition Report highlighted the Ethiopian Productive Safety Net Programme's efforts to make this large-scale intervention more nutrition sensitive. The 2015 Global Nutrition Report set out policies and interventions as well as indicators for nutrition-friendly food systems. But to date the Global Nutrition Reports have been relatively silent on what could make policies and interventions in food systems; the water, sanitation, and hygiene sector; and the education sector more nutrition oriented.

\section{Food systems}

The food system is vital for diet choices because it is an underlying driver of food availability, affordability, access, and acceptability. The food system includes agriculture, food distribution and transformation, and retail, as well as consumers.

The Global Nutrition Report 2015 examined different types of food systems and developed a dashboard of indicators for determining their nutrition sensitivity. But how do policy makers and civil society attempt to bring about these changes? There are choices in several policy domains. The type of agriculture and trade system a population has determines the nutritional quality of the food available (FAO 2015a). If it incentivizes the productivity and production of fruits and vegetables, then it is more likely that these will be grown and will be profitable, accessible, and affordable. The type of food distribution system will affect the accessibility of different types of foods. If, for example, fresh foods are more available only in places that require travel by car or public transport, accessibility will be diminished for the most marginalized. If fresh foods are much cheaper when bought in bulk, they will be less affordable to the poorest. If food transformation plays on and contributes to notions of desirability that are linked to 
products high in salt, sugar, and fat, then everyone will be at risk of consuming too many of these diet components. If purchasing power is improved though safety nets that favor the consumption of healthy foods, then the food system is helping to create a food environment that makes it easier for people to make healthy diet choices. Each of these food system components is shaped, in part, by public and private policy (see Chapters 4 and 7 of Global Nutrition Report 2015).

Table 6.3 shows how taking actions throughout food systems—not just in agriculture-could push food systems toward enabling and encouraging people to eat more nutritious, healthy diets. It includes just some of the potentially vast array of changes that could be made. Focusing on a small number of recommended dietary changes and just four different food system elements, it shows the importance of ensuring that actions are aligned for impact throughout food systems. Policies that aim to change consumer demand for food also affect food systems Some of these policies are included in Chapter 5 as well as discussed in Global Nutrition Report 2015.

One action that can be taken in the food distribution element of the food system is public procurement. Panel 6.2 on nutrition-sensitive public procurement of food illustrates what Brazil has done in an approach being adopted in different forms by many other countries around the world.

One possible action in the agricultural element of the food system is biofortification. By 2016, an estimated 15 million people were growing and eating biofortified foods (iron beans and pearl millet; zinc rice and wheat; and vitamin A sweet potatoes, cassava, and maize) in the eight countries where, for example, crops were first introduced through collaboration with HarvestPlus. These crops are now at a scaling-up stage. Panel 6.3 highlights some of the challenges to scaling up and how they might be overcome.

\section{TABLE 6.3 Some of the changes that can be made in food systems to achieve dietary goals}

\begin{tabular}{|c|c|c|c|c|}
\hline \multirow[b]{2}{*}{ Dietary goal } & \multicolumn{4}{|l|}{ Food system element } \\
\hline & Food production & $\begin{array}{l}\text { Food storage, transport, } \\
\text { distribution }\end{array}$ & $\begin{array}{l}\text { Cross-border food trade } \\
\text { and investment }\end{array}$ & $\begin{array}{l}\text { Food packaging and } \\
\text { processing }\end{array}$ \\
\hline $\begin{array}{l}\text { Increase fruit } \\
\text { and vegetable } \\
\text { intake }\end{array}$ & $\begin{array}{l}\text { Invest in mixed and integrated } \\
\text { cropping systems in areas } \\
\text { where markets are poorly } \\
\text { developed }\end{array}$ & $\begin{array}{l}\text { Invest in distribution } \\
\text { infrastructure to enable } \\
\text { establishment of local markets } \\
\text { for low-income groups; } \\
\text { develop public procurement } \\
\text { mechanisms to ensure fruits } \\
\text { and vegetables are served in } \\
\text { public institutions }\end{array}$ & $\begin{array}{l}\text { Use the World Trade } \\
\text { Organization Aid for Trade } \\
\text { initiative facility or Enhanced } \\
\text { Integrated Framework aid } \\
\text { for trade partnership to } \\
\text { increase the supply of fruits } \\
\text { and vegetables in low-income } \\
\text { countries }\end{array}$ & $\begin{array}{l}\text { Develop microenterprises for } \\
\text { local processing to reduce } \\
\text { waste }\end{array}$ \\
\hline $\begin{array}{l}\text { Increase intake } \\
\text { of legumes/ } \\
\text { pulses }\end{array}$ & Improve varieties to boost yield & $\begin{array}{l}\text { Train farmers on management } \\
\text { practices to reduce loss during } \\
\text { storage to insect damage/ } \\
\text { improper drying }\end{array}$ & $\begin{array}{l}\text { Safeguards to prevent } \\
\text { distortions that discourage } \\
\text { local production and regional } \\
\text { trade in legumes }\end{array}$ & $\begin{array}{l}\text { Develop quick-cooking bean } \\
\text { flours }\end{array}$ \\
\hline $\begin{array}{l}\text { Increase intake } \\
\text { of grains high } \\
\text { in protein, } \\
\text { micronutrients, } \\
\text { and fiber }\end{array}$ & $\begin{array}{l}\text { Incentivize the production } \\
\text { of underutilized grains; } \\
\text { promote biofortification using } \\
\text { conventional breeding }\end{array}$ & $\begin{array}{l}\text { Develop more efficient } \\
\text { threshing and milling } \\
\text { technologies for underutilized } \\
\text { grains }\end{array}$ & $\begin{array}{l}\text { Ensure that policies support } \\
\text { open regional trade where } \\
\text { neighboring countries produce } \\
\text { underutilized grains }\end{array}$ & $\begin{array}{l}\text { Set standards and marketing } \\
\text { incentives for use of whole } \\
\text { grains in processed food } \\
\text { products; develop novel foods } \\
\text { with underutilized species }\end{array}$ \\
\hline $\begin{array}{l}\text { Encourage } \\
\text { balanced } \\
\text { consumption of } \\
\text { safe milk }\end{array}$ & $\begin{array}{l}\text { Improve availability of animal } \\
\text { health services; ensure women } \\
\text { can have title to the animals } \\
\text { they milk and care for }\end{array}$ & $\begin{array}{l}\text { Invest in infrastructure to } \\
\text { ensure safe transport of milk } \\
\text { from farm to cooling center }\end{array}$ & $\begin{array}{l}\text { Ensure effective food safety } \\
\text { checks of imported milk } \\
\text { powder }\end{array}$ & $\begin{array}{l}\text { Train milk processors in food } \\
\text { safety and quality assurance }\end{array}$ \\
\hline $\begin{array}{l}\text { Replace } \\
\text { saturated and } \\
\text { trans fats with } \\
\text { unsaturated fats }\end{array}$ & $\begin{array}{l}\text { Switch investments in palm oil } \\
\text { to oils with healthier fatty acid } \\
\text { profiles }\end{array}$ & $\begin{array}{l}\text { Encourage cooperatives } \\
\text { between healthier oil } \\
\text { producers to lower prices }\end{array}$ & $\begin{array}{l}\text { Lower tariffs on healthier oils } \\
\text { relative to oils with saturated } \\
\text { fats }\end{array}$ & $\begin{array}{l}\text { Prohibit public investment } \\
\text { and disincentivize private } \\
\text { investment in facilities } \\
\text { producing hydrogenated oils }\end{array}$ \\
\hline $\begin{array}{l}\text { Reduce intake } \\
\text { of high-calorie, } \\
\text { nutrient-poor } \\
\text { sugary drinks } \\
\text { and salty snacks }\end{array}$ & $\begin{array}{l}\text { Use competition laws to } \\
\text { combat excessive concentration } \\
\text { in the agribusiness sector }\end{array}$ & $\begin{array}{l}\text { Tax transportation of high- } \\
\text { calorie, nutrient-poor sugary } \\
\text { drinks and salty snacks }\end{array}$ & $\begin{array}{l}\text { Codex Alimentarius } \\
\text { Commission sets international } \\
\text { guidelines for consumer- } \\
\text { friendly nutrition labels }\end{array}$ & $\begin{array}{l}\text { Mandate downsizing of } \\
\text { all package sizes of sugar- } \\
\text { sweetened beverages sold } \\
\text { through retail outlets }\end{array}$ \\
\hline
\end{tabular}

Source: Authors, adapted from information in Anand et al. (2015); Bereuter and Glickman (2015); de Schutter (2014); Fanzo et al. (2013); FAO (2013); Global Panel on Agriculture and Food Systems for Nutrition (2014); Hawkes and Ruel (2010); Hawkes (2015); Nugent (2011); UNSCN (2014). 


\section{PANEL 6.2 REORIENTING PUBLIC PROCUREMENT TOWARD NUTRITION: THE CASE OF BRAZIL}

\section{DANIEL BALABAN AND MARIANA ROCHA}

0 ver recent decades Brazil has experienced structural changes that have drastically transformed its nutrition landscape. These changes are the result of strong mobilization by both civil society and the government aimed at tackling hunger through a range of mechanisms, including the use of public procurement as a nutrition-sensitive policy.

In the 1980s, Brazil underwent a democratization process that culminated in the adoption of a new constitution in 1988. The so-called Citizen Constitution recognized numerous economic and social rights, such as the rights to health, education, housing, and social protection. As part of this trend toward a greater guarantee of rights and social mobilization, civil society started to bring attention to the issue of hunger. By channeling donations to those most in need while at the same time denouncing the government's lack of attention to this issue, social movements managed to put hunger on the government's agenda. In 1993-1994, the National Food and Nutrition Security Council (CONSEA) gathered government and civil society actors to advise the president on how to move this agenda forward, but the body was dissolved following a change in government.

In the following years, debate around undernutrition gained increasing recognition in the public space and was introduced to the agenda of certain political parties. By 2003, the newly elected government made combating hunger a major priority, with a dedicated approach. The Zero Hunger (Fome Zero) Strategy encompassed more than 20 initiatives in four axes of intervention to address the multiple causes and faces of hunger: food access, strengthening of smallholder farmers, income generation, and social control. Given the attention to civil society participation, CONSEA was reestablished. Overall, the strategy is considered a milestone in the recognition of food and nutrition as a leading and crosscutting priority on the political agenda.

The Food Acquisition Program (PAA) was designed within this framework to create public procurement markets for smallholder farmers. Through a simplified public bidding process, PAA lets food be procured from family farmers to meet the needs of food-insecure communities. Because family farmers participating in PAA mostly produce fresh products with little or no processing, fruits and vegetables are among the most important products purchased, promoting healthy eating habits among beneficiaries. The program is innovative because it created a major new market for smallholder farmers, who often have difficulty accessing markets and are themselves food insecure. While guaranteeing enhanced nutrition to vulnerable groups, PAA also contributes to farmers' food security by increasing their income.

In 2009, this model was incorporated into the existing National School Feeding Program (PNAE). The program was reshaped to promote the links between family farmers, food, and nutrition education in basic education. A quota of 30 percent of federal resources for school feeding had to be used to purchase food from family farmers. New nutritional criteria require nutritionally balanced meals for every age group, containing cooked and fresh food while avoiding processed foods with high levels of sodium, fat, and sugar. The new law also expanded targeted age groups by including the provision of complementary food to children between 6 months and 5 years old in preschools and nurseries-where up to 70 percent of the daily nutritional requirement should be met.

In the case of both PAA and PNAE, the facilitated bidding procedure for accessing public procurement is combined with technical assistance to these farmers, aligning other governmental areas with the broader strategy. Public authorities, including nutritionists, are also encouraged to prepare menus that incorporate local products and follow the production calendar in order to make procurement more functional to public institutions and farmers.

The PAA and PNAE have become an international reference on how to combine and link different programs to advance the nutrition of groups that are often among the most vulnerable. Brazil's experience is a good example of how public procurement may be shaped to contribute to social policies, increasing income and promoting greater inclusion. In addition to fostering shorter supply chains, which tend to be more sustainable and more inclusive of local cultural practices, such frameworks contribute directly to improving the nutrition of smallholder farmers and their families. In terms of institutional setting, the context in which PAA was created and PNAE was restructured bring to light how coordinated actions by different sectors of the government may be mutually reinforcing. The model is under consideration by more than 30 developing countries and has recently been endorsed by the African Union. The Purchase from Africans for Africa program implemented by Ethiopia, Malawi, Mozambique, Niger, and Senegal with technical leadership and expertise from the Food and Agriculture Organization of the United Nations and the World Food Programme is an example of how this model is being adapted by other countries (PAA Africa 2016). 


\section{PANEL 6.3 BIOFORTIFICATION: HOW TO SCALE UP?}

\section{HOWARTH BOUIS}

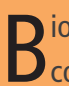
ofortification is the process of using conventional plant breeding techniques to enrich staple food crops with higher levels of vitamin A, zinc, and iron. Biofortified varieties are high yielding, profitable for farmers, and already available in a number of countries. Evaluations provide several examples of nutritional efficacy and effectiveness (van Jaarsveld et. al. 2005; Hotz et al. 2012; Beer et al. 2014; De Moura et al. 2014), and an increasing number of national and international institutions are mainstreaming biofortification into their policies and programs. African and Asian governments, the World Bank, the World Food Programme, and World Vision are increasingly convinced of the important role biofortified crops can have in improving the nutrition status of the most vulnerable. The International Potato Center has also been effective in broadening the reach of orange sweet potatoes through its programs and networks.

The key challenge to reaching the 1 billion poorest individuals with micronutrient deficiencies is to create sustained demand for the products. Strong demand for biofortified crops, among both consumers and policy makers, is the ultimate assurance that biofortification will be mainstreamed in agricultural research programs. Challenges to adoption so far have included (1) product color for high pro-vitamin A crops, which are yellow or orange, rather than the whiter color of comparable nonbiofortified varieties, and (2) a frequent perception that biofortified crops are genetically modified, whereas all crops officially released to date by national seed systems have been produced through traditional plant breeding techniques. Experience has shown that when information is provided to mothers, farmers, and policy makers, these challenges are no longer barriers.

Reaching 1 billion will involve repeating in another 25-30 countries (with a particular focus on the populous countries of Asia-and so also a focus on rice and wheat) what has worked well so far in 8 target countries. This will also entail broadening policy support among a number of national, regional, and international institutions, and expanding the number of organizations in those 25-30 countries that will mainstream biofortification in their core activities, a process that is already underway.

The first step is advocacy to begin to create demand for these products from policy makers, consumers, and researchers. The second step is to establish a country-specific pipeline of releases of high-yielding, high-profit biofortified crops through the national agricultural research system, private seed companies, or both. The CGIAR research centers are central to supporting this process, both through upstream plant breeding and through their extensive and long-standing networks with agricultural research institutions in developing countries. Finally, food subsidy policies could give preference to use of biofortified food staples. In the case of pro-vitamin A (orange/yellow) crops, consumers need to be informed of the reason for the color change through government programs and private-sector advertising. In the case of iron and zinc crops, the optimal strategy is to capture as high a percentage of the total supply as possible through piggybacking the high iron and zinc traits onto the highest-productivity, most climate-smart varieties available to farmers.

Nevertheless, resources are still needed - for advocacy, demand creation, and agricultural research — to help mainstream the uptake of biofortification. In the current eight target countries, donors have provided funding to initiate the delivery process, to learn lessons, and to prove principles in reaching the first 15 million. However, such funding is not available in unlimited amounts. Rather, spontaneous mainstreaming as described above is required for biofortification to spread more widely.

\section{Water, sanitation, and hygiene}

Recognition of the key role that low-quality water, sanitation, and hygiene (WASH) practices play in initiating and perpetuating malnutrition has grown substantially in the past 10 years (Bhutta et al. 2013; Ngure et al. 2014). For children, WASH programs are typically designed to either prevent feces from getting into the child's environment or prevent pathogens in the environment from being ingested (Curtis et al. 2000). Consequently, they achieve a host of health outcomes (infectious disease control, maternal and newborn health, child health and nutrition) by breaking this chain of enteric disease transmission.

Global rates of access to improved water and sanitation remain far from 100 percent (for improved sanitation, global access is 68 percent; for water, it is 91 percent [JMP 2015]), and 13 percent of the world's population practices open defecation (UNICEF and WHO 2015). Nonetheless, it is important to ask what can be done to make existing services more nutrition sensitive. While the evidence base is not yet strong in terms of completed studies, the framing for plausible design changes (Panel 6.4) is the same as 


\section{PANEL 6.4 MAKING WATER, SANITATION, AND HYGIENE PROGRAMS NUTRITION SENSITIVE}

\section{MDUDUZI MBUYA}

$\mathrm{M}$ aking water, sanitation, and hygiene (WASH) nutrition sensitive does not require a paradigm shift. Rather, it requires that interventionists and program planners adhere to WASH behavioral objectives and align programs with the multiple pathways of feco-oral transmission relevant to the target population. More specifically, here is how we can ensure that WASH programs are nutrition sensitive:

\section{Focus on nutritional outcomes:}

WASH programs inherently address crucial underlying drivers of fetal and child nutrition and development, and are therefore fundamentally nutrition sensitive. However, they can be further leveraged for nutrition actions when they are implemented in a manner that protects women's time; reducing the time women spend fetching water can affect the time they have available for childcare and other activities associated with improved consumption (Pickering and Davis 2012; WHO, UNICEF, and USAID 2015).

2. Target the first 1,000 days: The first 1,000 days after conception have been identified as a critical point in a child's development because of the rapid process of linear growth, which mirrors brain development. WASH programs targeted to this age group are therefore more likely to achieve nutritional outcomes and prevent the developmental deficits associated with early growth faltering.

3. Pay attention to the causal linkages between WASH and nutritional outcomes: Conditions of poor WASH can affect nutritional status through diarrheal disease and parasitic infections. Recently, it has been hypothesized that a subclinical gut disorder called environmental enteric dysfunction is a primary mediator of the association between WASH, and stunting and anemia (Humphrey 2009). Focusing only on clinical disease outcomes may thus underestimate the impact of WASH interventions. As such, WASH programs should be implemented with time frames that permit changes in nutritional outcomes to be realized and evaluated for additional outcomes related to diarrhea incidence and prevalence.

\section{Align WASH interventions with} these causal linkages: Preventing children's ingestion of fecal microbes in the first 1,000 days should be an express objective of nutrition-sensitive WASH programs. Research in rural Zimbabwe (Ngure et al. 2013; Mbuya et al. 2015) and elsewhere suggests that the feco-oral transmission pathways for adults differ from those of toddling children, who engage in mouthing and exploratory play-for example, geophagy and consumption of chicken feces. This result suggested that a nutrition-sensitive WASH (or baby WASH) intervention should

- reduce the environmental microbe load through household sanitation and hygiene;

- reduce fecal transmission via hands through washing of caregivers' and children's hands with soap;

- improve drinking water quality through improved access to protected water sources and hygienic methods of household water treatment and storage;

- promote exclusive breastfeeding for the first six months of life to ensure nutrient adequacy and exclude potentially contaminated non-breast milk liquids and foods;

- avoid child fecal ingestion during mouthing and exploratory play by ensuring a clean play and infant feeding environment; and

- provide hygienically prepared and stored complementary food fed using clean utensils and hands. for other underlying driver interventions: plan to improve nutrition status and prevent malnutrition.

Table 6.4 draws distinctions between conventional and nutrition-sensitive WASH programs. For example, nutrition-oriented WASH programs include interventions with the first 1,000 days postconception in mind. There is a greater focus on caregivers (those whom the baby is dependent on), on the cleanliness of play areas, and on preventing contact with animal as well as human feces (because infants crawl around with their hands on the floor).

\section{Humanitarian food assistance}

The number of people affected by disasters such as floods and droughts has shown no signs of diminishing in the first decade of the 21st century (Guha-Sapir et al. 2016). In 


\section{TABLE 6.4 Differentiating a nutrition-sensitive water, sanitation, and hygiene (WASH) program from a conventional WASH program}

\begin{tabular}{|c|c|c|}
\hline Feature & Conventional WASH & Nutrition-oriented WASH \\
\hline Primary outcomes of interest (impact indicators) & $\begin{array}{l}\text { Clinical disease outcome (for example, diarrhea, } \\
\text { trachoma, neglected tropical diseases) }\end{array}$ & $\begin{array}{l}\text { Nutritional outcome (for example, stunting, } \\
\text { anemia) in addition to clinical disease outcomes }\end{array}$ \\
\hline Primary target group & All age groups, communitywide & $\begin{array}{l}\text { The first } 1,000 \text { days from conception through two } \\
\text { years (focus is on caregivers, since the fetus/baby } \\
\text { is dependent on their actions) }\end{array}$ \\
\hline Infrastructural choices & Toilet, water supply & Toilet, water supply, protected play space \\
\hline Sources of contamination & Human feces & Human and animal feces \\
\hline Vectors of feco-oral transmission & $\begin{array}{l}\text { Fingers (with a focus on caregiver hands), fluids, } \\
\text { flies, fields }\end{array}$ & $\begin{array}{l}\text { Fingers (focusing on both caregiver and baby } \\
\text { hands), fluids, flies, fields (especially soil) }\end{array}$ \\
\hline Targeted behaviors (behavioral/process indicators) & $\begin{array}{l}\text { Disposal of feces, handwashing with soap, water } \\
\text { treatment, food hygiene }\end{array}$ & $\begin{array}{l}\text { Disposal of feces (with added emphasis on } \\
\text { animal stool and child feces), handwashing } \\
\text { with soap (focusing on both caregiver and baby } \\
\text { hands), water treatment, food hygiene, exclusive } \\
\text { breastfeeding }\end{array}$ \\
\hline $\begin{array}{l}\text { Factors influencing choice of combinations of } \\
\text { intervention components }\end{array}$ & $\begin{array}{l}\text { Communicable disease prevention or control; } \\
\text { ministerial or donor priorities }\end{array}$ & Nutritional outcomes \\
\hline Evidence base & Strong randomized trial evidence & $\begin{array}{l}\text { Strong observational evidence base and } \\
\text { plausibility basis }\end{array}$ \\
\hline
\end{tabular}

Source: Mduduzi Mbuya.

addition, the Intergovernmental Panel on Climate Change estimates that climate change will increase the frequency and severity of such events (IPCC 2007).

The El Niño weather events of 2015-2016 have already been devastating for millions, especially in eastern and southern Africa (FAO 2016a), and will reverberate throughout 2016 as families struggle to cope with the effects the droughts and floods have had on food production, food prices, and rural livelihoods (WFP 2016). Panel 6.5 summarizes some of the challenges and lessons from responding to El Niño in 2015. The effects of El Niño will be lifelong for those in the first 1,000 days postconception, whose growth and development could not be protected from El Niño's effects (see, for example, Danysh et al. 2014). In addition, and as data from the UN High Commissioner for Refugees reported in Chapter 8 show, the number of people displaced by conflict has reached an unprecedented high (nearly 60 million). Chapter 8 will ask how accountability to those vulnerable to emergencies can be improved. Here we ask how well the humanitarian food assistance strategies of different agencies are doing in mainstreaming nutrition and thereby mainstreaming commitments to reducing undernutrition in emergencies.

The improvement of nutrition status of disaster-affected populations is widely acknowledged to require action beyond the nutrition sector (von Grebmer et al. 2015; Brown et al. 2015). As the recent analysis by Brown and colleagues noted, "There is a need to tackle the multiple determinants of undernutrition in emergencies through the mainstreaming of nutrition across sectors including in humanitarian food assistance" $(2015,7)$.

Supported by the European Commission's Humanitarian Aid and Civil Protection department (ECHO), Brown and colleagues (2015) reviewed 22 policy and strategy documents from 2006 to 2015 from UN agencies, international nongovernmental organizations, and donors on 15 criteria. Figure 6.3 shows the percentage of documents that "covered" each of the 15 criteria. The 22 strategy and policy documents did especially poorly in three criteria or areas: monitoring coverage or access of groups (especially the most vulnerable) to nutrition-sensitive humanitarian food assistance (HFA) interventions; minimizing unintended negative nutritional impacts from nutrition-sensitive HFA; and references to meeting Sphere minimum (voluntary) standards in food security and nutrition, which promote accountability in the humanitarian space on these issues. HFA agencies can strengthen their commitments in the above areas, preferably by pooling capacity and resources with their development counterparts (Panel 6.5 also stresses this point). 


\section{PANEL 6.5 THE EL NIÑO CLIMATE CYCLE: SUCCESSES AND CHALLENGES FROM 2015}

\section{YVES HORENT, CLAIRE DEVLIN, AND ABIGAIL PERRY}

The impact of El Niño on malnutrition

throughout 2015 and into 2016 has been profound, resulting in a staggering caseload of severe acute malnutrition (UNICEF 2016a) in eastern and southern Africa and an estimated 60 million people affected overall so far (UNOCHA 2016). The full impacts on hunger and malnutrition are poorly understood but will undoubtedly be significant and long lasting. The events of the past year have highlighted that despite some improvements, systems are still not able to sufficiently mitigate the impact of the types of climatic shocks arising from El Niño.

Like other organizations, the UK Department for International Development (DFID) started to monitor El Niño models closely beginning with the first warning in March 2015. At that time forecasts were uncertain, but they reached a much higher degree of certainty in June 2015. This was the point at which the predicted likelihood of a strong event became sufficient to inform early decisions. Over this period, DFID, scientists, academics, and the UK Meteorology Office collaborated to anticipate weather patterns and possible humanitarian effects. In August 2015, this scientific analysis started to be shared with donors as well as development and humanitarian agencies to stimulate early response. Starting in October 2016, qualityassured regional seasonal outlooks were also provided to interested partners.

Mindful of the devastating impacts of the 1997-1998 and 2010-2011 El Niño episodes, the focus during this period was developing or updating contingency plans (DFID 2015). It was apparent that there would be major nutrition needs across parts of Africa and other regions. The hunger crisis in the Horn of Africa in 2010-2011 highlighted that early warning does not automatically lead to early action, and the country contingency plans were identified as a crucial step for stimulating action.

In view of the large numbers of people affected by El Niño in 2015 and 2016, it is evident that more progress is urgently required:

- Contingency planning and other preparedness activities need to be timely and more systematic and methodological. These should not be the exclusive responsibility of emergency humanitarian agencies but need to be integrated into a wider range of government departments, agencies, and programs.

- Evidence on the design and delivery of shock-responsive social protection needs to be enhanced to enable rapid expansion to more crisis-prone countries. If possible, these mechanisms should also be made more nutrition sensitive and linked to early warning systems that enable localized prediction of hunger and malnutrition.

- The use of climate science needs to become the norm and more systematic. This requires more people to be educated and trained to understand forecasts and stick to quality-assured products. These also need to be better communicated to all decision makers, from the grassroots level up to heads of state, in a language that is appropriate.

- Financing mechanisms are needed that trigger the release of resources at scale and on time.

- Analysis of economic and market data needs to be strengthened. New technologies should facilitate access to data and analysis, leading to greater transparency and adaptation of policy at times of stress or shocks.

The 2015-2016 El Niño is not, however, an entirely bad-news story. Despite the weaknesses in the response this time around, there is evidence that there have been important improvements in our ability to deal with climatic shocks when compared with the experience of the $\mathrm{El}$ Niño in 1997-1998:

- With more knowledge and more computer power, weather forecasts have significantly improved and are much more reliable, over longer periods of time and in more regions than ever. Forecasts are also better communicated, thanks to new information technologies.

- Many countries have improved their disaster management capacity, and the aid sector has become much more structured and professional. More decision makers understand the benefits of early actions and more collaboration.

- More countries have social protection programs that not only partially sheltered large numbers of people from the impact of climatic shocks but can also rapidly adapt and be scaled up when needed (Fitzgibbon 2016).

- New risk-based financing models are also being tested and are providing promising results.

While an El Niño of the strength seen in 2015-2016 is not a common occurrence, the distortions to weather patterns are not dissimilar to a near-future world with climate change. Vital lessons have been learned over the past year, and we will need to build upon these to improve our ability to protect populations from hunger and malnutrition into the future. 


\section{FIGURE 6.3 Percentage of 22 policy and strategy humanitarian food assistance documents that cover nutrition-sensitive issues in different domains}

\begin{tabular}{rr}
\hline & Advocacy for wider national or global policy change \\
Communication of importance and results
\end{tabular}

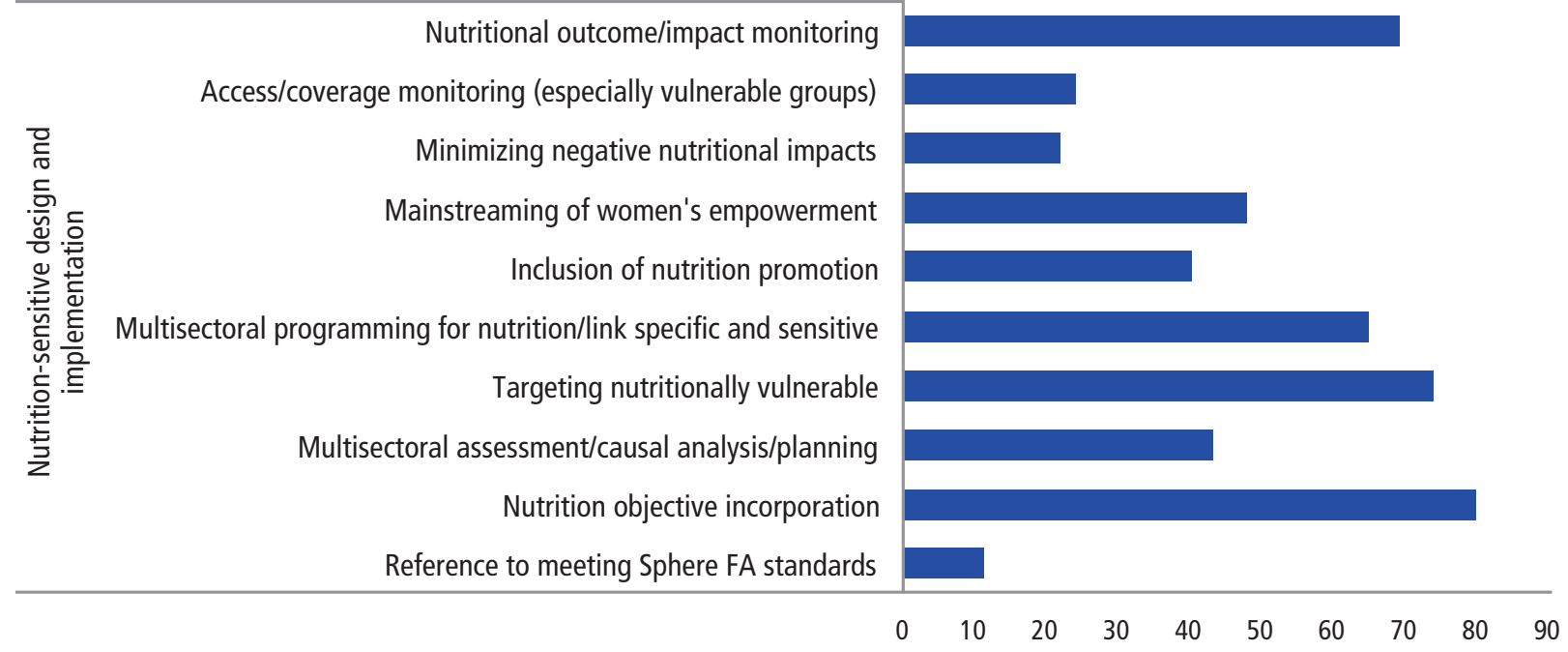

Source: Brown et al. 2015.

Note: $F A=$ food assistance.

\section{USING UNDERLYING DETERMINANT INTERVENTIONS AND POLICIES AS A PLATFORM FOR DIRECT NUTRITION ACTIONS}

Here we consider the usefulness of underlying determinant interventions and policies as platforms for the more direct or nutrition-specific actions highlighted in Chapter 5.

\section{Cash transfers with behavior change}

New research from Bangladesh illustrates the potential impact of using social protection interventions as a platform for direct nutrition interventions. World Food Programme cash transfers that added behavior change communications around infant and young child feeding were the only type of transfer that had a large, positive, and significant impact on height-for-age Z-scores. Cash transfers without behavior change communications did not have an impact on height-for-age scores, although nearly all modalities had a positive impact on household food security and child diet (Ahmed et al. 2016). This evaluation of the cash transfer modalities was a trial of a pilot program, but given the widespread implementation of cash transfer programsand if the results are replicated-the inclusion of behavior change components in social protection programs shows promise.

\section{Education}

The education sector provides opportunities for improving nutrition through all three of the pathways identified in the chapter introduction: the level of underlying drivers, the nutrition sensitivity of drivers, and the use of underlying determinant interventions as platforms for direct nutrition interventions. It is an important way of empowering women and of changing norms about nutrition. Panel 6.6 outlines what the options are and what the evidence says. 


\section{PANEL 6.6 INCREASING THE ORIENTATION OF EDUCATION ACTIONS TOWARD ADDRESSING MALNUTRITION IN ALL ITS FORMS}

\section{HAROLD ALDERMAN}

$\mathrm{N}$ utrition-sensitive programs draw upon complementary sectors to affect the underlying determinants of nutrition and child development, which include poverty, food insecurity, and lack of access to adequate care resources and adequate health, water, and sanitation services (Ruel and Alderman 2013). While particular attention has been applied to the potential nutrition sensitivity of agriculture and social protection, education shares in that potential owing to its coverage as well as its ability to serve as a platform for nutrition-specific programs. There are several ways to make school more nutrition sensitive.

Increase girls' participation in schooling. Girls' schooling can reduce adolescent pregnancy-a welldocumented risk factor for small birth size (Kozuki et al. 2013)—as well as raise the age of marriage (Hahn et al. 2015) and reduce total fertility (Breierova and Duflo 2004). Clearly, however, in the long run what girls learn in school is even more important. This is not just basic literacy and numeracy, but also information on health and nutrition.

Use school as a platform for nutrition education and other nutrition-related services. There is accumulating evidence on school-based modules for nutrition education, particularly in encouraging healthy eating and exercise with the aim of preventing obesity (Waters et al. 2011). There is also some experience with encouraging hygiene and handwashing as well as with teaching modules addressing risky activities potentially linked to adolescent pregnancies. But there is also one glaring omission: there is little in the nutrition literature that covers low- and middle-income countries on the experience of using classrooms to impart information on caring for children, despite the high expectation that most students will shortly take on the role of caregiver (Tang et al. 2009).

Schools can also be a platform for iron supplementation (Luo et al. 2012) as well as for incentives for school leaders to reduce anemia in schools (Miller et al. 2012). Similarly, albeit not without some debate, schools can provide a platform for regular deworming (Ahuja et al. 2015).

Make school meals a nutrition intervention. School meals offer a possibility for exploring diet diversity, but their role in improving nutrition is less straightforward than their proven role in promoting school enrollment. This is illustrated by the example of certain Mexican children who can be classified as both underweight by World Health Organization (WHO) standards and simultaneously overweight in terms of body mass index (Lobstein et al. 2015). This paper offers an apt phrase for the challenge that this phenomenon exemplifies - overweight or underheight? - a challenge that affects the goals and assessment of school feeding programs, including those in preschools. It is no longer clear how to interpret evidence such as the systematic review of randomized trials of school meals that reported an increased weight gain of 0.39 kilograms (Kristjansson et al. 2007) without a greater understanding of context, although the corresponding evidence on school performance in these programs is less ambiguous (Victora and Rivera 2014).

Use school feeding as a potential support to agricultural development. In addition to its nutrition, education, and social protection objectives, school feeding is increasingly asked to support agricultural development through homegrown school feeding programs. Adding a new objective, of course, increases the tradeoffs that must be considered. In the case of homegrown school feeding, decentralization makes fortification - one means by which school meals can effectively reduce micronutrient deficiencies-more challenging, but not impossible. It also increases the challenge of logistics in food-insecure areas in times of drought or seasonal shortages. Over time, however, homegrown school feeding may improve dietary diversity and increase food security among low-income producers, although there is no evidence yet to support this hope.

\section{CALLS TO ACTION}

1. Set targets for underlying driver outcomes. During the next revision of their national nutrition and noncommunicable disease plans, country governments and civil society organizations (CSOs) should identify the primary underlying drivers of their unique nutrition contexts and establish targets to accelerate improvement in them.

\section{Set targets for nutrition-sensitive spending.}

Governments, UN agencies, CSOs, donors, and businesses should make more ambitious commitments about the percentages of their investments in food systems; water, sanitation, and hygiene (WASH); education; gender equity; and social protection programs that are explicitly designed to help address all forms of malnutrition. 


\section{Deepen understanding of common drivers of poor}

nutrition. Researchers need to create a unified, conceptual framework for understanding the underlying drivers of overweight/obesity, micronutrient deficiency, stunting, and wasting - and identify common drivers of all forms of malnutrition. This will help guide specific commitments by governments, donors, the UN, and businesses at the underlying level. This should be published in a Lancet nutrition series and supported by funders and governments.

4. Strengthen nutrition action for those affected by conflict and emergencies. Leading national and international humanitarian stakeholders must ensure that their actions are more nutrition oriented, and they need to do a better job of

- monitoring access of vulnerable groups to humanitarian interventions that tackle malnutrition and bridge the gap between humanitarian and development interventions;

- meeting Sphere standards on the implementation of humanitarian response in food and nutrition as a way to strengthen accountability to vulnerable groups; and

- systematically using climate science, social protection mechanisms, and new data technologies to improve the ability of underlying drivers to improve preparedness for and response to shocks.

These stakeholders should be encouraged to make SMART commitments in the aforementioned areas as part of the 2016 N4G process, and as they set country-level SDG targets. 